\title{
Effect of a participatory intervention in women's self-help groups for the prevention of chronic suppurative otitis media in their children in Jumla Nepal: a cluster-randomised trial
}

\author{
Susan Clarke ${ }^{1 *}$, Robyn Richmond ${ }^{1}$, Heather Worth', Rajendra Wagle² and Andrew Hayen ${ }^{3}$
}

\begin{abstract}
Background: Chronic suppurative otitis media (CSOM) causes preventable deafness and disproportionately affects children living in poverty. Our hypothesis was that health promotion in women's groups would increase their knowledge, attitudes and practices (KAP) regarding ear disease and reduce the prevalence of CSOM in their children.

Methods: We did a cluster randomised trial in two village development committees (VDCs) in Jumla, Nepal. In July 2014, 30 women's groups were randomly allocated to intervention or control, stratified by VDC and distance to the road. The intervention groups participated in three sessions of health promotion using the WHO Hearing and Ear Care Training Resource Basic Level. The primary outcome was women's KAP score and the secondary outcome was prevalence of CSOM in their children at 12 month follow-up. Analyses were by intention to treat. Participants and the research team were not masked to allocation.
\end{abstract}

Results: In June and July 2014 we recruited 508 women and 937 of their children. 12 months later there was no difference in the women's KAP score (mean difference $0.14,95 \% \mathrm{Cl}-0.1$ to $0.38, P=0.25$ ) or the prevalence of CSOM in their children (OR 1.10,95\% 0.62 to $1.84, P=0.75)$ between intervention and control groups. However, overall, there was a significant improvement in the KAP score (mean difference $-0.51,95 \% \mathrm{Cl}-0.71$, to -0.31 , $P<0.0001)$ and in the prevalence of CSOM from baseline $11.2 \%$ to follow-up $7.1 \%(P<0.0001)$.

Conclusions: Health promotion in women's groups did not improve maternal KAP or reduce prevalence of CSOM. Over time there was a significant improvement in women's KAP score and reduction in the prevalence of CSOM which may be attributable to our presence in the community offering treatment to affected children, talking to their parents and providing ciprofloxacin drops to the local health posts. More research is needed in low resource settings to test our findings.

Trial registration: Australia and New Zealand Clinical Trial Registry 12,614,000,231,640; Date of registration: 5.3.2014: Prospectively registered.

Keywords: Otitis media, Children, Nepal, Health promotion

\footnotetext{
* Correspondence: susan.clarke@unswalumni.com

'School of Public Health and Community Medicine, University of New South

Wales Sydney, High St, Kensington, NSW 2052, Australia

Full list of author information is available at the end of the article
}

(c) The Author(s). 2019 Open Access This article is distributed under the terms of the Creative Commons Attribution 4.0 International License (http://creativecommons.org/licenses/by/4.0/), which permits unrestricted use, distribution, and reproduction in any medium, provided you give appropriate credit to the original author(s) and the source, provide a link to the Creative Commons license, and indicate if changes were made. The Creative Commons Public Domain Dedication waiver (http://creativecommons.org/publicdomain/zero/1.0/) applies to the data made available in this article, unless otherwise stated. 


\section{Background}

Chronic suppurative otitis media (CSOM) is a multifactorial disease of poverty. Globally, CSOM affects 65 to 330 million people, of whom at least $50 \%$ suffer clinically significant hearing loss [1]. Hearing loss can interfere with early childhood development and decrease educational and social opportunities compounding the existing disadvantage of marginalised children [2]. Therefore, effective strategies for preventing CSOM in low resource settings are urgently needed.

Otitis media is a spectrum of disease beginning with an acute respiratory infection leading to acute otitis media and otitis media with effusion, which can result in a chronic perforation of the tympanic membrane, chronic inflammation of the middle ear cavity and otorrhoea or discharge (CSOM) [1]. Appropriate treatment of acute otitis media with oral antibiotics and early treatment of CSOM with topical antibiotics and ear mopping are simple, inexpensive and effective [3]. The prevalence of CSOM in Nepal is 5 to $10 \%$ in the available studies which mostly rely on cross-sectional groups of school children in less remote settings or patients attending ear, nose and throat specialist clinics [4-7]. Every study that has been conducted in Nepal has revealed a prevalence above the $4 \%$ level satisfying the WHO definition of a 'massive public health problem' requiring 'urgent attention' [1].

Nepal is in the lower third of countries for human development (HDI 0.574, rank 149 out of 189) [8]. However, poverty remains 'highly asymmetric' in Nepal with the western regions and the mountains having poorer outcomes on every measure $[9,10]$. Jumla is one of the most disadvantaged districts of Nepal, with an HDI of 0.409 , a rank of 68 out of 75 districts [11]. CSOM is strongly associated with poverty and its social determinants including: low parental education level, low parental income, malnutrition, overcrowding, lack of access to clean water and sanitation $[12,13]$.

Until now, there has been little research into prevention of CSOM in low resource settings, leading to calls to have it added to the other 17 neglected tropical diseases [14]. Like the neglected tropical diseases, CSOM disproportionately affects people living in poverty causing significant morbidity, could be amenable to public health intervention and is neglected by research. A range of community based interventions have been successful in improving maternal and child health outcomes in low resource settings [15]. To our knowledge, the effectiveness of a community based educational intervention to improve the ear health of children has not previously been tested in a controlled trial. We hypothesised that in the disadvantaged mountain district of Jumla a community based intervention would improve the knowledge, attitudes and practices of women regarding ear disease and reduce the prevalence of CSOM in their children.

\section{Methods}

\section{Study design}

We conducted a cluster randomised trial using women's self-help groups as the units of randomisation and individual women and their children as the units of analysis. A CRT was a suitable study design because the intervention was delivered at the cluster level and to reduce experimental contamination. The study protocol is published and we adhered to the CONSORT guidelines extension for cluster randomised trials for the study design and analysis $[16,17]$. The study setting consisted of two village development committees (VDCs) in the remote mountain district of Jumla, Nepal. VDCs are the smallest local government division in Nepal and consist of 3000 to 5000 people. The pre-existing women's self-help groups were facilitated by a local non-government organisation (NGO) which had been working in health and community development in Jumla for many years.

\section{Participants}

The participants were women attending existing women's self-help groups in Jumla and their household children aged 12 years and under. The only exclusion criterion was women who were unable to give informed consent. The research process was verbally explained to the participants individually and they individually gave verbal and written informed consent for themselves and their children. In addition to the parental consent, children over the age of 7 years also gave verbal and written assent as required by Nepal Health Research Council. A small donation of \$US10 was contributed to each study group's savings. Women were free to opt out of the study at any time. We aimed to enrol all group members as they would be receiving the intervention at their regular monthly meetings.

\section{Randomisation and masking}

We randomly selected 30 women's self-help groups from a total of 57 groups and then randomly allocated the 30 study groups to the trial arms. Randomisation was conducted by a public health officer in the district health office in Jumla, who had no other role in the research using Excel random number generator. Randomisation was stratified by VDC and distance to the road, to ensure that we included equal proportions of groups from both VDCs and from the most remote villages. All women in the study groups and their children aged 12 years and under were invited to participate by the NGO staff. Because of the pragmatic nature of the intervention, neither participants nor field-workers could be masked to study group allocation. The follow-up data was collected 12 months after the intervention. 


\section{Procedures}

The existing women's self-help groups meet monthly to develop action plans for community problems, deposit into the group savings and participate in health education. Health education is facilitated by the NGO staff on topics such as the importance of breastfeeding, child nutrition, handwashing and safe food storage. All 30 study groups met as usual each month. The control groups received the usual education session while the intervention groups participated in additional ear health education over three consecutive group meetings. The lead author delivered the Sessions 1 and 2 with the assistance of an interpreter when needed. Session 3 was delivered by the NGO group facilitators.

Session 1 was an interactive education session in the women's self-help groups using a flip-book containing local photographs following the sections in the WHO Primary Ear and Hearing Care Resource Basic Level [18]. The book focused on identification of a child with an ear infection, the causes and complications of ear infections and the consequences of hearing loss. We encouraged care-givers to attend the health post if they thought their child had an ear infection. Session 2 was a practical session consisting of hands-on ear mopping and the correct installation of eardrops, along with reinforcement of the messages from the first session. The lead author and the interpreter demonstrated on each other and then the women practised on each other. The women were very engaged in this session and actively participated, asking questions and sharing experiences. Session 3 was a brief recap of sessions one and two and included a small laminated card for each woman to take home with pictures of ear-wicking and drop installation in a child's discharging ear.

\section{Outcomes}

The primary outcome was the knowledge, attitudes and practices questionnaire score at 12 month follow-up assessment. The secondary outcome prevalence of childhood CSOM at the 12 month follow-up assessment. Ancillary outcomes included before and after analysis and further analysis of children's anthropometry, socioeconomic status, caste and gender.

The primary outcome was assessed by a questionnaire that we developed since there was no existing validated tool (Additional file 1). The questionnaire was informed by the literature and includes validated questions from the demographic health survey and multiple indicator cluster survey $[10,19]$. It contains demographic questions such as age, gender, number of children, maternal education, food security and usual health practices, followed by questions about knowledge, attitudes and practices regarding ear health, hearing, ear disease and healthcare seeking. The questionnaires were completed on paper in Nepali by trained research assistants.

For the secondary outcome, we used the WHO definition of CSOM as 'a chronic inflammation of the middle ear and mastoid cavity, which presents with recurrent otorrhoea through a tympanic membrane perforation, with at least 2 weeks of otorrhoea [1]. The lead author performed all of the ear examinations at baseline and follow-up. We collected images of tympanic membranes Cellscope-Oto smartphone enabled digital otoscope for blinded analysis. We offered a general health check to all of the children and the trained research assistants performed height, weight and visual acuity examinations. Children with ear infections were offered treatment with ciprofloxacin drops.

\section{Statistical analysis}

Using data extracted from our initial qualitative research, the sample size was 114 women in each arm for an unclustered study with a 5\% two-sided Type 1 error and $80 \%$ power to detect a $25 \%$ difference in mean knowledge, attitudes and practices scores. The cluster sizes were set at the size of the women's groups, at around 20 women. There was no directly comparable ICC in the literature, so studies on other aspects of child health were considered in Nepal [20]. We used the safe equation DEff $=1+(m-1) \rho$, assuming $\rho=0.05$, which would give a $\operatorname{DEff}=1.95$, or 223 women per arm. This would translate into 11 clusters per arm. To account for clustering and loss to follow-up, a conservative 15 clusters per arm were recruited.

The primary outcome, the knowledge, attitudes and practices at follow-up assessment, was analysed using general estimating equations (GEE), which adjust for clustering because groups rather than individuals were randomised. Covariates from the literature including socioeconomic status, caste, parental education and nutritional status were also considered using GEE. The secondary outcome, the prevalence of CSOM at followup assessment, was similarly analysed using GEE.

We also performed several ancillary analyses. Further analysis of a comparison of baseline and follow-up data was carried out using standard statistical techniques, including simple $t$-tests for the continuous knowledge, attitudes and practice data and McNemar's test for our binary data. Similarly, several important correlates were examined individually using similar standard techniques. Analysis was by intention-to-treat using SPSS version 25 . Since there were no potential harms from the intervention there was no data monitoring committee.

\section{Results}

We recruited 30 groups, which comprised 508 women and 937 of their children between Jun 1, 2014 and Jul 
31, 2014. Figure 1 presents the cluster and individual participant flow. Follow-up assessment was performed on $449(88.4 \%)$ of the women and $748(79.8 \%)$ of their children.

Table 1 shows the baseline characteristics of the women and children. The mean age of the women was 34.3 (SD 11.3) years, they had 3.4 children (SD 1.6) and more than half $(52.8 \%)$ of the women had received no education. Intervention and control groups were similar on all measures except for caste. More women in the intervention groups belonged to Dalit caste $(115,42.8 \%)$ compared to control group (58, 24.3\%). Women in 22 of the 30 clusters belonged to a single type of caste, either Brahman/Chhetri or Dalit, while three groups had one or two other caste members and two other groups had four or five. The completely Brahman/Chhetri groups were equally distributed in the intervention and control groups (eight in the intervention and nine in the control) but the completely Dalit groups were not (six in the intervention and two in the control). Therefore, since randomisation was performed by group, there were more women of Dalit caste in the intervention group than in the control group. Table 2 shows the baseline characteristics of the clusters. The intervention and control clusters were similar on all measures except for caste. Intervention groups had a mean of 7.7 Dalit women per group and control groups had a mean of 4.8 women per group.

We analysed the primary outcome at both the cluster and individual level (see Table 3). The main analysis using GEE and the null model gave non-significant results (mean difference $=0.14,95 \% \mathrm{CI}-0.10$ to $0.38, P=$ 0.25 ), as did the model that included geographical stratification (mean difference $=0.15,95 \%$ CI -0.09 to 0.38 , $P=0.21)$. VDC 1 consistently had KAP lower scores in this model (mean difference $=-0.78,95 \% \mathrm{CI}-1.0$ to $0.55, P<0.0001)$. The ICC was 0.14 , indicating a large degree of clustering.

Table 4 shows the GEE analysis of the covariates of the primary outcome demonstrating no significant difference

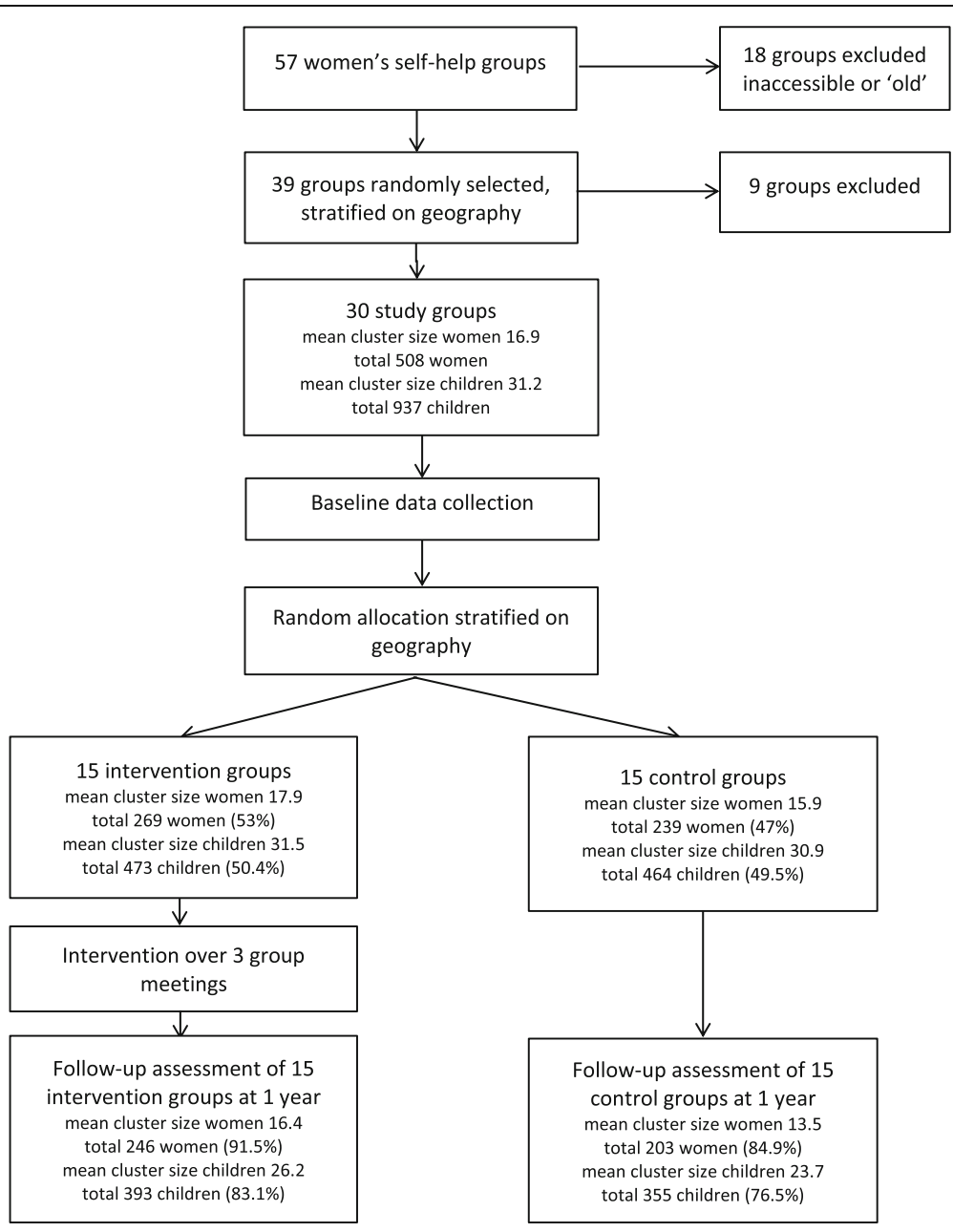

Fig. 1 Flow of participants through the trial 
Table 1 Baseline characteristics of women and children

\begin{tabular}{|c|c|c|c|}
\hline & Intervention & Control & Total \\
\hline Number of women $(\%)^{*}$ & $269(53)$ & $239(47)$ & 508 \\
\hline Number of clusters & 15 & 15 & 30 \\
\hline Cluster size (mean, SD) & $17.9(2.3)$ & $15.9(3.3)$ & $16.9(3.0)$ \\
\hline Age of women (mean, SD) & $33.8(11.5)$ & $34.9(11.0)$ & $34.3(11.3)$ \\
\hline $\begin{array}{l}\text { Number of children per } \\
\text { woman (mean, SD) }\end{array}$ & $3.3(2.3)$ & $3.5(1.6)$ & $3.4(1.6)$ \\
\hline \multicolumn{4}{|l|}{ Women's caste (\%) } \\
\hline Dalit & $115(42.8)$ & $58(24.3)$ & $173(34.1)$ \\
\hline Brahman/Chhetri & $154(57.2)$ & $181(75.7)$ & $335(65.9)$ \\
\hline Household size (mean, SD) & $6.1(2.6)$ & $6.1(2.6)$ & $6.1(2.6$ \\
\hline $\begin{array}{l}\text { Area household land in hals } \uparrow \\
\text { (mean, SD) }\end{array}$ & $3.3(2.3)$ & $3.6(3.5)$ & $3.4(3.0)$ \\
\hline $\begin{array}{l}\text { Number of household cattle } \\
\text { and buffalo (mean, SD) }\end{array}$ & $3.6(2.5)$ & $3.8(2.9)$ & $3.7(2.7)$ \\
\hline $\begin{array}{l}\text { Any smoking inside the } \\
\text { house (\%) }\end{array}$ & $151(56.1)$ & $120(50.2)$ & $271(47.1)$ \\
\hline \multicolumn{4}{|c|}{ Highest education level women (\%) } \\
\hline None & $232(86.2)$ & $205(85.8)$ & $437(86)$ \\
\hline Some primary & $21(7.8)$ & $15(6.3)$ & $36(7.1)$ \\
\hline Some secondary & $16(5.8)$ & $19(7.9)$ & $35(6.9)$ \\
\hline \multicolumn{4}{|c|}{ Highest education level husband (\%) } \\
\hline None & $149(55.4)$ & $119(49.8)$ & $268(52.8)$ \\
\hline Some primary & $46(17.1)$ & $55(23)$ & $101(19.9)$ \\
\hline Some secondary & $74(27.5)$ & $65(27.3)$ & $139(27.4)$ \\
\hline $\begin{array}{l}\text { Any antenatal care last } \\
\text { pregnancy }(\%)\end{array}$ & $238(88.5)$ & $220(92.1)$ & $458(90.2)$ \\
\hline \multicolumn{4}{|l|}{ Location of last birth (\%) } \\
\hline In the cowshed & $72(26.8)$ & $71(29.7)$ & $143(28.1)$ \\
\hline Inside the house & $126(46.9)$ & $113(47.3)$ & $239(47.1)$ \\
\hline At a health facility & $62(23.1)$ & $49(20.5)$ & $111(21.8)$ \\
\hline $\begin{array}{l}\text { Ever taken a child to traditional } \\
\text { healer (\%) }\end{array}$ & $124(46.1)$ & $109(45.6)$ & $233(45.9)$ \\
\hline \multicolumn{4}{|l|}{ Number of participant children (\%) } \\
\hline Total & $473(50.5)$ & $464(49.5)$ & 937 \\
\hline Girls & $241(51)$ & 229.(49.4) & $470(49.8)$ \\
\hline Boys & $232(49)$ & $235(50.6)$ & $467(50.2)$ \\
\hline Age of children (mean, SD) & $6.5(3.5)$ & $6.5(3.5)$ & $6.5(3.5)$ \\
\hline \multicolumn{4}{|c|}{ Children's anthropometry (mean, SD) } \\
\hline Weight of children in $\mathrm{kg}$ & $17.31(6.95)$ & $17.72(7.19)$ & $17.51(7.07)$ \\
\hline Weight-for-age $z$-score & $-1.86(1.07)$ & $-1.88(1.04)$ & $-1.9(1.05)$ \\
\hline Height of children in cm & $\begin{array}{l}106.47 \\
(21.21)\end{array}$ & $\begin{array}{l}108.03 \\
(21.95)\end{array}$ & $\begin{array}{l}107.22 \\
(21.57)\end{array}$ \\
\hline Height-for-age $z$-score & $-2.05(1.36)$ & $-1.97(1.28)$ & $-2.0(1.33)$ \\
\hline \multicolumn{4}{|l|}{ Children's ear examination (\%) } \\
\hline Any CSOM & $53(11.2)$ & $53(11.4)$ & $106(11.3)$ \\
\hline Any acute otitis media & $5(1.1)$ & $13(2.8)$ & $18(1.9)$ \\
\hline $\begin{array}{l}\text { Any dullness or retraction } \\
\text { eardrum }\end{array}$ & $37(7.8)$ & $67(14.4)$ & $104(11.2)$ \\
\hline
\end{tabular}

between the KAP score in the intervention or control groups (mean difference $=0.14,95 \% \mathrm{CI}-0.10$ to $0.38, P=$ 0.27). Women of Dalit caste, who lived in VDC 2, and those with a larger number of children and number in household were all associated with a higher KAP score. Measures of socioeconomic status (amount of land and number of large animals owned) were not associated with the outcome; nor were smoking inside or the level of education reached by the woman or her husband.

The secondary outcome was prevalence of CSOM in the children at 12-month follow-up. Overall, 53 (7.1\%) out of 748 children were suffering CSOM at follow-up assessment, 29 (7.4\%) in the intervention group and 24 (6.8\%) in the control group. There were 37 children with unilateral and 16 children with bilateral CSOM, and the prevalence increased with age. Forty of the children had experienced discharge for more than 12 weeks and 29 had done so for one year or more, and there was no difference in the mean duration of discharge between the intervention and control groups. (mean difference 2.83 weeks, $95 \%$ CI 62.52 to $68.19, P=0.931$ ). Table 5 shows the analysis of the secondary outcome. The unadjusted GEE showed OR 1.10 (95\% CI 0.62 to $1.92, P=0.75$ ). When adjusted for stratification the GEE model produces an OR of 1.12 (95\% CI 0.64 to $1.96, P=0.70)$. The ICC for the secondary binomial outcome was 0.06 .

Next, we analysed the secondary outcome covariates using GEE (see Table 6). The null model includes the variables of geographical stratification VDC and distance to the health post, as well as group type. In the null model there was no difference between the intervention and control groups in the prevalence of CSOM at follow-up, OR $1.12,95 \%$ CI 0.64 to $1.96, P=0.76$ and for the model overall $X^{2}(1, n=748)=0.15, \quad P=0.70$. BMI-for-age $z$-score delivered an OR of $0.52,95 \% \mathrm{CI}$ 0.34 to $0.79, P=0.003$, and was the largest predictor in this model. The number of large animals was statistically significant but the odds ratio was very close to 1 , which is a very small predictor in this model. Other measures of socioeconomic status, caste, education, smoking or geography did not make a unique contribution to the model.

We then compared the overall baseline and follow-up results. Firstly, for the primary outcome, we compared the mean of individual women's baseline KAP score with the mean of their follow-up KAP scores using the paired samples $t$-test. The overall follow-up mean (mean $=7.72$, $\mathrm{SE}=0.48)$ was significantly greater than the overall baseline mean $($ mean $=7.21, \mathrm{SE}=0.08)$ KAP score (mean difference $=-0.51,95 \% \mathrm{CI}-0.71$ to $-0.31, t(446)=-5.07$, $P<0.0001)$. Secondly, we compared the overall baseline and follow-up prevalence of CSOM in the children. There were $106(11.3 \%, n=937)$ cases of CSOM in the baseline examination and $53(7.1 \%, n=749)$ in the 
Table 2 Baseline characteristics of clusters (women's self-help groups)

\begin{tabular}{|c|c|c|c|}
\hline & Intervention & Control & Total \\
\hline Number of clusters (women's self-help groups) & 15 & 15 & 30 \\
\hline Mean number of women in clusters (SD) & $17.93(2.25)$ & $15.93(3.28)$ & $16.93(2.97)$ \\
\hline \multicolumn{4}{|l|}{ Number of clusters in each VDC } \\
\hline VDC 1 & 5 & 5 & 10 \\
\hline VDC 2 & 10 & 10 & 20 \\
\hline \multicolumn{4}{|l|}{ Numbers of clusters at distance to the health post $(\mathrm{N})$} \\
\hline Less than one hour & 12 & 10 & 22 \\
\hline One hour or more & 3 & 5 & 8 \\
\hline Mean age of women in clusters (mean, SD) & $33.58(3.48)$ & $35.15(2.03)$ & $34.36(2.91)$ \\
\hline \multicolumn{4}{|l|}{ Number of children per woman (mean, SD) } \\
\hline Total & $3.26(0.39)$ & $3.47(0.39)$ & $3.37(0.49)$ \\
\hline Girls & $1.76(0.38)$ & $1.81(0.24)$ & $1.79(0.32)$ \\
\hline Boys & $1.52(0.29)$ & $1.66(0.36)$ & $1.59(0.33)$ \\
\hline Mean number of women of Dalit caste per cluster (SD) & $7.67(8.04)$ & $4.80(5.74)$ & $6.23(7.02)$ \\
\hline Household size (mean, SD) & $6.06(0.91)$ & $6.15(0.90)$ & $6.10(0.89)$ \\
\hline Area of household land in hals (mean, SD) & $3.29(1.03)$ & $3.39(1.47)$ & $3.34(1.25)$ \\
\hline Number of household cattle and buffalo (mean, SD) & $3.72(1.23)$ & $3.73(1.36)$ & $3.72(1.22)$ \\
\hline Mean number of households with indoor smoking per cluster (SD) & $9.80(3.41)$ & $7.80(3.47)$ & $8.80(3.53)$ \\
\hline \multicolumn{4}{|l|}{ Highest education level woman (mean, SD) } \\
\hline None & $15.47(3.16)$ & $13.67(2.77)$ & $14.57(3.06)$ \\
\hline Some primary & $1.47(1.13)$ & $1.20(1.27)$ & $1.33(1.18)$ \\
\hline Some secondary & $1.0(1.60)$ & $1.07(1.53)$ & $1.03(1.54)$ \\
\hline \multicolumn{4}{|l|}{ Highest education level husband (mean, SD) } \\
\hline None & $9.93(4.52)$ & $7.93(3.60)$ & $8.93(4.14)$ \\
\hline Some primary & $3.13(1.81)$ & $3.67(2.09)$ & $3.40(1.94)$ \\
\hline Some secondary & $4.93(4.10)$ & $4.33(3.48)$ & $4.63(3.75)$ \\
\hline Any antenatal care last pregnancy (mean, SD) & $15.87(3.09)$ & $14.67(3.66)$ & 15.27 (3.38) \\
\hline \multicolumn{4}{|l|}{ Location of last birth (mean, SD) } \\
\hline In the cowshed & $4.80(3.73)$ & $4.73(3.08)$ & $4.77(3.36)$ \\
\hline Inside the house & $7.53(4.94)$ & $7.53(4.94)$ & $7.97(4.85)$ \\
\hline At a health facility & $4.20(2.54)$ & $3.80(2.40)$ & $4.0(2.44)$ \\
\hline Ever taken child to traditional healer (mean, SD) & $8.27(3.58)$ & $7.27(4.54)$ & $7.77(4.05)$ \\
\hline \multicolumn{4}{|l|}{ Mean number of participant children per cluster (SD) } \\
\hline Total & $31.53(9.23)$ & $30.93(9.85)$ & $31.23(9.39)$ \\
\hline Girls & $16.07(6.49)$ & $15.27(6.11)$ & $15.67(6.21)$ \\
\hline Boys & $15.47(4.75)$ & $15.67(5.65)$ & $15.57(5.13)$ \\
\hline Age of children (mean, SD) & $6.48(1.05)$ & $6.49(1.05)$ & $6.49(0.96)$ \\
\hline \multicolumn{4}{|l|}{ Children's anthropometry (mean, SD) } \\
\hline Weight of children in kg & $17.28(1.87)$ & $17.23(2.01)$ & $17.26(1.91)$ \\
\hline Weight-for-age $z$-score & $-1.96(0.33)$ & $-1.93(0.33)$ & $-1.95(0.33)$ \\
\hline Height of children in cm & $106.51(6.16)$ & $107.50(6.01)$ & $107.0(6.0)$ \\
\hline Height-for-age $z$-score & $-2.09(0.41)$ & $-1.98(0.34)$ & $-2.03(0.37)$ \\
\hline
\end{tabular}


Table 2 Baseline characteristics of clusters (women's self-help groups) (Continued)

\begin{tabular}{|c|c|c|c|}
\hline & Intervention & Control & Total \\
\hline \multicolumn{4}{|l|}{ Children's ear examination (mean, SD) } \\
\hline Any CSOM & $3.67(1.76)$ & $3.40(2.06)$ & $3.53(1.89)$ \\
\hline Any acute otitis media & $0.33(0.62)$ & $0.87(1.06)$ & $0.6(0.89)$ \\
\hline Any dullness or retraction eardrum & $2.67(1.95)$ & $4.27(3.20)$ & $3.47(2.73)$ \\
\hline
\end{tabular}

follow-up examination. Using McNemar's test to compare two related categorical variables, there was a significant reduction in the overall prevalence of CSOM at follow-up $(P<0.0001)$.

\section{Discussion}

To our knowledge, this is the first cluster randomised trial to assess a community based intervention to prevent CSOM in a low to middle income country. In Jumla Nepal, health promotion in existing women's self-help groups did not increase the women's KAP for their children's ear health or reduce the prevalence of CSOM in the children. However, there was significant overall improvement in KAP score and reduction in the prevalence of CSOM that was equal in both the intervention and control groups at 12 month followup. Our trial was powered to detect small effects and the intervention was delivered as planned so it is likely that the lack of increase in KAP and reduction of CSOM in the intervention group was a true null effect. Therefore, either our hypothesis that our health promotion would improve

Table 3 Comparison of women's KAP scores at 12 month followup in the intervention and control groups, using cluster-level summaries and individual-level regression analysis

\begin{tabular}{lll}
\hline & Unadjusted analysis & Adjusted analysis \\
\hline Cluster-level analysis & & \\
Mean difference & 0.03 & 0.06 \\
$95 \% \mathrm{Cl}$ & -0.41 to 0.47 & 0.41 to 0.30 \\
$P$ value & 0.88 & 0.75 \\
Linear regression unadjusted for clustering & \\
Mean difference & -0.14 & -0.15 \\
$95 \% \mathrm{Cl}$ & -0.39 to 0.10 & -0.39 to 0.09 \\
$P$ value & 0.26 & 0.23 \\
Mixed effects linear regression & \\
Mean difference & 0.12 & 0.14 \\
$95 \% \mathrm{Cl}$ & -0.36 to 0.61 & -0.28 to 0.56 \\
$P$ value & 0.61 & 0.49 \\
Generalised estimating equations & \\
Mean difference & 0.14 & 0.15 \\
$95 \% \mathrm{Cl}$ & -0.10 to 0.38 & -0.09 to 0.38 \\
$P$ value & 0.25 & 0.21 \\
\hline
\end{tabular}

adjusted for VDC and distance from the road
KAP and reduce CSOM was flawed or there were other confounding conditions.

Despite the null result from the intervention, there was a significant overall small increase in the women's KAP score and a large decrease in the children's prevalence of CSOM, from 11.3 to $7.1 \%$. Although we cannot ascribe causality to this result with certainty the control group did receive an informal intervention by participating in the trial itself. The global research emphasises the difficulty of reducing CSOM, so it is most unlikely that a relative risk reduction of $37 \%$ in 1 year is a natural improvement [21]. The control group met the team, answered the survey questions twice in a 12-month period and allowed us to examine their children. When we found a child with any kind of ear disease we spoke to their parents, explained the disease, discussed treatment in detail and either gave them ciprofloxacin eardrops or referred them to the health post for oral antibiotics. There is evidence that just being asked about your behaviour can change it, a phenomenon called 'mere measurement', which may have affected women in the control group and this attribution effect has been found in many studies. In addition, the effect of this 'much better than usual care' might have been so powerful that it obscured the potential effect of the formal intervention [22].

Our study had important strengths. Our study was set among remote village women and children with a high burden of disease who are under-served by research. Our intervention was embedded in the local community, low-cost and easily reproducible in many contexts. We had a high follow-up rate and consistency in the delivery of the intervention. There was a significant equal increase in KAP scores and reduction in the prevalence CSOM in the both study groups suggesting that this was a genuine effect. Our study also had limitations. Our participants were unable to be blinded as to group allocation and our presence in the community and interest in ears was widely known. Some clusters were very near and could have contaminated the outcomes. We offered treatment to any child who presented with CSOM at any time during the study and referred any with acute otitis media to health services which, although ethically correct, potentially contaminated our findings.

The global research on prevention of CSOM is scanty, despite its morbidity and occasional mortality among disadvantaged people. Like our study, several promising 
Table 4 Covariates of women's KAP score at 12 month follow-up in the intervention and control groups, using generalised estimating equation (GEE)

\begin{tabular}{|c|c|c|c|c|c|c|}
\hline \multicolumn{7}{|l|}{ Parameter estimates } \\
\hline \multirow[t]{2}{*}{ Parameter } & \multirow[t]{2}{*}{ B } & \multirow[t]{2}{*}{ SE } & \multirow[t]{2}{*}{$95 \%$ Wald Cl } & \multicolumn{3}{|l|}{ Hypothesis test } \\
\hline & & & & Wald chi-square & df & $P$ \\
\hline (Intercept) & 7.583 & 0.3248 & 6.947 to 8.220 & 545.114 & 1 & 0.001 \\
\hline Group (control vs intervention) & 137 & 0.1230 & -0.104 to 0.378 & 1.241 & 1 & 0.265 \\
\hline VDC (1 vs 2$)$ & -0.868 & 0.1301 & -1.123 to -0.613 & 44.490 & 1 & 0.001 \\
\hline Distance to health post ( $<1 \mathrm{~h} v \mathrm{v} \geq 1 \mathrm{~h}$ ) & 0.110 & 0.1455 & -0.175 to 0.395 & 0.571 & 1 & 0.450 \\
\hline Caste (Dalit vs Brahmin/Chhetri) & 0.491 & 0.1611 & 0.175 to 0.806 & 9.271 & 1 & 0.002 \\
\hline Woman education (none vs some) & -0.145 & 0.1882 & -0.514 to 0.224 & 0.593 & 1 & 0.441 \\
\hline Husband education (none vs some) & -0.040 & 0.1471 & -0.328 to 0.248 & 0.074 & 1 & 0.786 \\
\hline Smoking inside (infrequently/never vs daily) & -0.142 & 0.1344 & -0.405 to 0.122 & 1.113 & 1 & 0.291 \\
\hline Age of woman & -0.012 & 0.0066 & -0.025 to 0.001 & 3.365 & 1 & 0.067 \\
\hline No. children per woman & 0.175 & 0.0597 & 0.058 to 0.292 & 8.620 & 1 & 0.003 \\
\hline No. in household & 0.059 & 0.0294 & 0.001 to 0.116 & 3.994 & 1 & 0.046 \\
\hline Household land (hals) & -0.021 & 0.0216 & -0.063 to 0.022 & 0.926 & 1 & 0.336 \\
\hline No. cattle, buffalo, horses & -0.034 & 0.0231 & -0.079 to 0.012 & 2.127 & 1 & 0.145 \\
\hline
\end{tabular}

interventions have not been able to demonstrate their effectiveness. CSOM is a complex condition that reflects the interaction of marginalisation, poverty, malnutrition, quality of health services, access to education and the inequity of health research. One reported trial tested the 'Breathing, blowing, coughing' exercise to clear mucus at

Table 5 Comparison of the prevalence of CSOM in children in the intervention and control groups at 12 month follow-up using cluster-level summaries and individual-level regression analyses

\begin{tabular}{lll}
\hline & \multicolumn{1}{c}{ Unadjusted analysis } & Adjusted analysis $^{\mathrm{a}}$ \\
\hline Cluster-level summary analysis & \\
Mean difference & -0.33 & 0.32 \\
$95 \% \mathrm{Cl}$ & -1.41 to 0.75 & -0.82 to 1.45 \\
$P$ value & 0.53 & 0.57 \\
Logistic regression unadjusted for clustering & \\
Odds ratio & 1.10 & 1.12 \\
$95 \% \mathrm{Cl}$ & 0.63 to 1.98 \\
$P$ value & 0.63 to 1.92 & 0.71 \\
Logistic regression with random effects & \\
Odds ratio & 1.07 & 1.09 \\
$95 \% \mathrm{Cl}$ & 0.62 to 1.84 & 0.63 to 1.89 \\
$P$-value & 0.80 & 0.76 \\
Generalised estimating equations & 1.12 \\
Odds ratio & 1.10 & 0.64 to 1.96 \\
$95 \% \mathrm{Cl}$ & 0.62 to 1.92 & 0.70 \\
$P$-value & 0.75 &
\end{tabular}

adjusted for VDC and distance from the road the beginning of the school day which continues to be used in schools in remote Australian Aboriginal communities. Teachers reported 'less snot' there was no reduction in CSOM [23]. Similarly, the introduction of community swimming pools was hypothesised to reduce CSOM by passive ear toilet, but studies have shown no effect on the prevalence of CSOM [24]. Zinc supplementation has been unsuccessful [25] and even the screening program for Aboriginal children in New South Wales, Australia, has not provided evidence of a reduction in the prevalence of CSOM [26]. The failure of these studies to reduce the prevalence of CSOM demonstrates the difficulty of research into and management of CSOM. Therefore, our overall relative reduction of $37 \%$ is both meaningful and unique.

There are two interventions for the prevention of CSOM which have been successful and both use medication, so are very different to our community based intervention. In Nepal, Vitamin A was given to preschoolers for the prevention of blindness, and a sample were followed into adulthood. Schmitz et al. (2012) [27] found that malnourished pre-schoolers with discharging ears who were given Vitamin A had a $42 \%$ reduction in hearing loss in adulthood. The mechanism of this effect is not understood and all children in Nepal receive Vitamin A. The second intervention that has been shown to possibly reduce CSOM is pneumococcal immunisation which continues to be evaluated, with current reductions in acute otitis media of 6 to $43 \%$ reported from developed nations [28]. In addition, successful clinical treatment programs such as the Earbus in Western Australia report significant reductions in CSOM but 
Table 6 Covariates of prevalence of CSOM at 12 month follow-up in the intervention and control groups using generalised estimating equation (GEE)

\begin{tabular}{|c|c|c|c|c|c|c|c|}
\hline \multirow[t]{2}{*}{ Parameter } & \multirow[t]{2}{*}{ B } & \multirow[t]{2}{*}{ SE } & \multicolumn{3}{|l|}{ Hypothesis test } & \multirow{2}{*}{$\begin{array}{l}\text { Odds } \\
\text { ratio }\end{array}$} & \multirow[t]{2}{*}{$95 \% \mathrm{Cl}$} \\
\hline & & & Wald chi-square & $d f$ & $P$ & & \\
\hline (Intercept) & -4.72 & 1.19 & 15.68 & 1 & 0.001 & 0.009 & 0.001 to 0.09 \\
\hline Group (control vs intervention) & 0.30 & 0.46 & 0.42 & 1 & 0.52 & 1.345 & 0.55 to 3.28 \\
\hline VDC (1 vs 2$)$ & 0.58 & 0.48 & 1.41 & 1 & 0.23 & 1.78 & 0.69 to 4.59 \\
\hline Distance to health post ( $<1 \mathrm{~h}$ vs $\geq 1 \mathrm{~h}$ ) & 0.45 & 0.57 & 0.63 & 1 & 0.43 & 1.57 & 0.52 to 4.75 \\
\hline Caste (Dalit vs Brahmin/Chhetri) & 0.21 & 0.53 & 0.16 & 1 & 0.69 & 1.24 & 0.44 to 3.49 \\
\hline Woman's education (none vs some) & 0.63 & 0.77 & 0.66 & 1 & 0.42 & 1.87 & 0.41 to 8.50 \\
\hline Area of household land (hals) & -0.24 & 0.14 & 2.78 & 1 & 0.10 & 0.79 & 0.60 to 1.04 \\
\hline Number of cattle, buffalo, horses & 0.16 & 0.07 & 4.43 & 1 & 0.04 & 1.17 & 1.01 to 1.35 \\
\hline Woman's age & -0.01 & 0.06 & 0.01 & 1 & 0.91 & 0.99 & 0.88 to 1.12 \\
\hline Children's BMI-for-age $z$ score & -0.66 & 0.22 & 9.07 & 1 & 0.003 & 0.52 & 0.34 to 0.79 \\
\hline
\end{tabular}

need community engagement, skilled staff and intensive follow-up which is difficult to achieve in low resource settings such as Jumla [29].

The baseline prevalence of CSOM in our study (11.3\%) was higher than in other studies in children in Nepal [4-7]. However, there are no other recent studies measuring the prevalence of CSOM in children in similarly remote and disadvantaged places in Nepal. Similar to the Nepal studies, the prevalence of CSOM children in Bangladesh and India is 3 to $6 \%$, while Indigenous children in remote Australia and Greenland have the highest rates of CSOM, 8 to $17 \%$ [30]. Therefore, the baseline prevalence in our study population was very high on world standards, probably explained by the degree of poverty and remoteness of Jumla.

Future research might explore adapting our materials to assess maternal knowledge, attitudes and practices at earlier time points to assess whether knowledge degraded over time. Local primary health service providers could be included in the study and usage could also be assessed to triangulate practice data. In addition, since CSOM is a chronic variable condition, longer term followup and a focus on younger children would be useful.

\section{Conclusions}

There was a significant improvement in the women's KAP for ear health and a significant reduction in CSOM in their children at 12 months, equal in both study groups. We were not able to reject the null hypothesis that the intervention based on WHO Primary Ear and Hearing Care Resource [18] would improve outcomes. Our 'contamination' of the control group in ethically examining and treating children with CSOM, talking to their parents, stocking the local health post, this 'much better than usual care' may have contributed to the overall reduction in prevalence of CSOM, obscuring the effect of the formal intervention [22]. More research is urgently needed in low-resource setting to prevent the life-changing hearing loss of this neglected disease of disadvantage.

\section{Additional file}

Additional file 1: Clarke et al., Jumla CSOM questionnaire. Original English questionnaire developed by Clarke et al., then translated into Nepali for use in Jumla, Nepal. (DOCX 25 kb)

\section{Abbreviations}

CSOM: Chronic suppurative otitis media; GEE: General estimating eqs.; HDI: Human development index; KAP: Knowledge, attitudes and practices; NGO: Non-government organisation; VDC: Village development committee; WHO: World Health Organisation

\section{Acknowledgements}

We would like to thank the women of Jumla for their enthusiastic participation, and Samjhana Shahi and the team at Jumla International Nepal Fellowship for their encouragement and support throughout the research.

\section{Funding}

The corresponding author was supported by the University of New South Wales, School of Public Health and Community Medicine Domestic Research PhD Scholarship. The funding did not play a role in the design, collection or analysis of the data presented in this study.

Availability of data and materials

The datasets analysed during the current study are available from the corresponding author on reasonable request.

\section{Authors' contributions}

Study design: SC, RR, HW, AH, RW; Data collection and Nepal supervision: SC, RW; Data analysis: SC, RR, AH; All authors read and approved the final manuscript.

\section{Ethics approval and consent to participate}

Ethical approval was obtained from ethics committee of the Nepal Health Research Council (\#1454) and the Human Research Ethics Council, University of New South Wales Sydney (\#13361). All participants gave verbal and written informed consent.

Consent for publication

Not applicable 


\section{Competing interests}

The authors declare that they have no competing interests.

\section{Publisher's Note}

Springer Nature remains neutral with regard to jurisdictional claims in published maps and institutional affiliations.

\section{Author details}

'School of Public Health and Community Medicine, University of New South Wales Sydney, High St, Kensington, NSW 2052, Australia. ${ }^{2}$ Institute of Medicine, Tribhuvan University, Maharaganj, Kathmandu, Nepal. ${ }^{3}$ Faculty of Health, University of Technology Sydney, 15 Broadway, Ultimo, NSW 2007, Australia.

Received: 28 November 2018 Accepted: 14 May 2019

Published online: 23 May 2019

\section{References}

1. World Health Organization. Chronic suppurative otitis media: burden of illness and management options. Geneva: World Health Organization; 2004. Retrieved from http://www.who.int/pbd/publications/Chronicsuppurative otitis_media.pdf

2. Lieu JE, Tye-Murray N, Karzon RK, Piccirillo JF. Unilateral hearing loss is associated with worse speech-language scores in children. Pediatr. 2010; 125:e1348-55.

3. Macfadyen C, Acuin J, Gamble C. Systematic review comparing systemic antibiotics and topical treatments for chronically discharging ears with underlying eardrum perforations, in participants of any age. Cochrane Database Syst Rev. 2006;1. https://doi.org/10.1002/14651858.CD005608.

4. Adhikari P. Pattern of ear diseases in rural school children: experiences of free health camps in Nepal. Int J Pediatr Otorhinolaryngol. 2009;73:1278-80. https://doi.org/10.1016/j.ijporl.2009.05.020.

5. Adhikari P, Joshi S, Baral D, Kharel B. Chronic suppurative otitis media in urban private school children of Nepal. Braz J Otorhinolaryngol. 2009;75: 669-72.

6. Maharjan M, Bhandari S, Singh I, Mishra S. (2006). Prevalence of otitis media in school going children in eastern Nepal. Kathmandu Univ Med J. 2006;4: 479-82.

7. Rijal A, Joshi R, Regmi S, Malla N, Dhungana A, Jha A, Rijal J. Ear diseases in children presenting at Nepal medical college teaching hospital. Nepal Med Coll J. 2011:13:164

8. United Nations Development Programme. Human development report 2016: human development for everyone. New York: United Nations Development Programme; 2016. Retrieved from http://hdr.undp.org/en/ 2016-report

9. Chin B, Montana L, Basagana X. Spatial modeling of geographic inequalities in infant and child mortality across Nepal. Health Place. 2011;17:929-36. https://doi.org/10.1016/j.healthplace.2011.04.006.

10. Ministry of Health and Population, New ERA, \& ICF. Nepal Demographic and Health Survey 2016: Key Indicators. Kathmandu: Ministry of Health Nepal, 2017. Retrieved from https://dhsprogram.com/publications/publicationFR336-DHS-Final-Reports.cfm. Accessed 1 Mar 2018.

11. United Nations Development Programme, \& Government of Nepal National Planning Secretariat. Nepal Human Development Report 2014: .Beyond Geography: Unlocking Human Potential. Kathmandu: United Nations Development Programme, Government of Nepal National Planning Commission Secretariat, 2014. Retrieved from http://www.hdr.undp.org/ sites/default/files/nepal_nhdr_2014-final.pdf. Accessed 18 Aug 2017.

12. Shaheen MM, Raquib A, Ahmad SM. Chronic suppurative otitis media and its association with socio-economic factors among rural primary school children of Bangladesh. Indian J Otolaryngol Head Neck Surg. 2012;64:36-41. https://doi.org/10.1007/s12070-011-0150-9.

13. Sophia A, Isaac R, Rebekah G, Brahmadathan K, Rupa V. Risk factors for otitis media among preschool, rural Indian children. Int J Pediatr Otorhinolaryngol. 2010;74:677-83. https://doi.org/10.1016/j.jporl.2010.03.023.

14. Li MG, Hotez PJ, Vrabec JT, Donovan DT. Is chronic suppurative otitis media a neglected tropical disease? PLoS Negl Trop Dis. 2015;9:e0003485. https:// doi.org/10.1371/journal.pntd.0003485.

15. Prost A, Colbourn T, Seward N, Azad K, Coomarasamy A, Copas A, ... Lewycka S. Women's groups practising participatory learning and action to improve maternal and newborn health in low-resource settings: A systematic review and meta-analysis. Lancet 2013; 381: 1736-1746

16. Campbell MK, Piaggio G, Elbourne DR, Altman DG. (2012). Consort 2010 statement: extension to cluster randomised trials. BMJ. 2012;e5661:345. https://doi.org/10.1136/bmj.e5661.

17. Clarke S, Richmond R, Worth H, Wagle R. A study protocol for a cluster randomised trial for the prevention of chronic suppurative otitis media in children in Jumla, Nepal. BMC Ear, Nose Throat Dis. 2015;15. https://doi.org/ 10.1186/s12901-015-0017-x

18. World Health Organization. Primary ear and hearing care training resource. Switzerland: World Health Organisation, 2006. Retrieved from http://www. who.int/pbd/deafness/activities/hearing_care/en/

19. Central Bureau of Statistics. Nepal Multiple Indicator Cluster Survey 2010 Mid and Far Western Regions, Final Report. Kathmandu: Central Bureau of Statistics, UNICEF Nepal, 2012. Retrieved from microdata.worldbank.org/index php/catalog/1310. Accessed 26 Oct 2013.

20. Mullany LC, Darmstadt GL, Khatry SK, et al. Topical applications of chlorhexidine to the umbilical cord for prevention of omphalitis and neonatal mortality in southern Nepal: a community-based, cluster- randomised trial. Lancet. 2006;367: 910-8.

21. Jensen $\mathrm{RG}$, Koch $\mathrm{A}$, Homøe P. Long-term tympanic membrane pathology dynamics and spontaneous healing in chronic suppurative otitis media. Pediatr Inf Dis J. 2012;31:139-44.

22. Lock M, Nguyen VK. An anthropology of biomedicine. Malden, MA: WileyBlackwell; 2010. p. 185

23. Barker $\mathrm{R}$, Thomas D. A practical intervention to address ear and lung disease in aboriginal primary school children of Central Australia. J Paediatr Child Health. 1994;30:155-9.

24. Hendrickx D, Stephen A, Lehmann D, Silva D, Boelaert M, Carapetis J, Walker R. A systematic review of the evidence that swimming pools improve health and wellbeing in remote aboriginal communities in Australia. Aust N Z J Public Health. 2016;40:30-6. https://doi.org/10.1111/1753-6405.12433.

25. Gulani A, Sachdev HS. Zinc supplements for preventing otitis media. Cochrane Database of Syst Rev. 2014;6. https://doi.org/10.1002/14651858. CD006639.pub4

26. ARTB Consultants Evaluation of the Aboriginal Otitis Media Screening Programme. Report for the NSW Department of Health. Sydney: ARTB Consultants; 2008

27. Schmitz J, West KP Jr, Khatry SK, et al. Vitamin a supplementation in preschool children and risk of hearing loss as adolescents and young adults in rural Nepal: randomised trial cohort follow-up study. BMJ. 2012;344:1-12. https://doi.org/10.1136/bmj.d7962.

28. Pettigrew M, Alderson M, Bakaletz L, et al. Panel 6: Vaccines. Otolaryngol Head Neck Surg. 2017;156(suppl 4):S76-87. https://doi.org/10.1177/ 0194599816632178 .

29. Bhutta M. Models of service delivery for ear and hearing care in remote or resource-constrained environments. J Laryngol Otol. 2019;133:39-48. https:// doi.org/10.1017/S0022215118002116.

30. Homøe P, Kværner K, Casey J, et al. Panel 1: Epidemiology and diagnosis. Otolaryngol Head Neck Surg. 2017;156(suppl 4):S1-S21. https://doi.org/10. $1177 / 0194599816643510$
Ready to submit your research? Choose BMC and benefit from:
- fast, convenient online submission
- thorough peer review by experienced researchers in your field
- rapid publication on acceptance
- support for research data, including large and complex data types
- gold Open Access which fosters wider collaboration and increased citations
- maximum visibility for your research: over 100M website views per year
At BMC, research is always in progress.
Learn more biomedcentral.com/submissions 